\title{
Effect of rapid thermal annealing on properties of contacts Au-Mo-TiB $\mathbf{x}_{\mathbf{x}}-\mathrm{GaAs}$
}

\author{
E.F. Venger, A.A. Beliaev, N.S. Boltovets*, I.B. Ermolovich, V.N. Ivanov*, R.V. Konakova, \\ V.V. Milenin, D.I.Voitsikhovski**, T. Figielski**, A. Makosa** \\ Institute of Semiconductor Physics NAS of Ukraine, Kiev, Ukraine \\ *State Scientific-Research Institute «Orion», Kiev, Ukraine \\ **Institute of Physics, Polish Academy of Sciences, 02-668 Warsaw, Poland
}

\begin{abstract}
The analytical, structural and electrophysical techniques have been applied to studies of the thermal degradation mechanism appearing in diode structures with the Schottky barrier $\mathrm{Au}-\mathrm{Mo}-\mathrm{TiB}_{\mathrm{x}^{-}}$ GaAs. It was shown that the rapid thermal annealing at $T=600{ }^{\circ} \mathrm{C}$ during $60 \mathrm{sec}$ in hydrogen atmosphere results in creating the ELS type center in the space charge region of GaAs. This center is represented by the complex $V_{\mathrm{Ga}}+V_{\mathrm{As}}$, which has been confirmed by photoluminescence measurements. It causes the appearance of excess current at the initial part of current-voltage characteristic.
\end{abstract}

Keywords: metal-semicond contact, rapid thermal annealing, deep centers.

Paper received 02.07.99; revised manuscript received 06.09.99; accepted for publication 04.10.99.

\section{Introduction}

In the last few years the contacts based on inclusion phases are more often used for solving the problem of thermal reliability of gallium arsenic diodes with Schottky barrier. The main advantage of these contacts is the absence of interaction between the components of the contact metal-GaAs up to very high temperatures. $\mathrm{TiB}_{\mathrm{x}}$ films are typically used for metallization of this type. The $\mathrm{TiB}_{\mathrm{x}}$ layers with a reproducible and controllable composition are obtained using the magnetron sputtering technique [1-3]. However, despite a great amount of information about $\mathrm{TiB}_{\mathrm{x}}$ films and their modifications, the studies of thermal stability of these objects in the contacts $\mathrm{TiB}_{\mathrm{x}}-\mathrm{GaAs}$ are practically absent. In this paper the thermal stability of parameters of Schottky barriers $\mathrm{Au}-\mathrm{Mo}-\mathrm{TiB}_{\mathrm{x}}-\mathrm{GaAs}$ has been investigated by structural and electrophysical techniques.

\section{Methods of sample preparation and measurements}

The samples were fabricated on epitaxial $n-n^{+}$structures of GaAs (100), doped by tellurium to $2 \cdot 10^{18} \mathrm{~cm}^{-3}$ in the substrate and to $3 \cdot 10^{16} \mathrm{~cm}^{-3}$ in $n$-layer, thicknesses of the substrate and epitaxial layer being 300 and $2.5 \mu \mathrm{m}$, respectively. $\mathrm{TiB}_{2}$ layer was deposited onto the surface of the epitaxial film after the photon cleaning using magnetron sputtering of pressed powder targets in argon or in the mixture of argon and nitrogen. Then the Au and Mo layers with thickness of $0.05 \mu \mathrm{m}$ each were deposited. Ohmic contacts were created by deposition and annealing in hydrogen at $T=450^{\circ} \mathrm{C}(60 \mathrm{~s})$ of AuGe eutectic. Part of samples were annealed during $60 \mathrm{~s}$ in the flow of hydrogen at $T=400$ and $600{ }^{\circ} \mathrm{C}$.

The samples of both types (as-deposited and annealed at $T=400$ and ${ }^{\circ} 600 \mathrm{C}$ during $60 \mathrm{~s}$ in hydrogen atmosphere) represented the test structures for structural, analytical experimental techniques and for photoluminescense (PL) measurements. The diode structures with diameter $250 \mu \mathrm{m}$ mounted in open metal-ceramic cases were also studied.

The forward and reverse current-voltage characteristics (IVC), capacitance-voltage characteristics (CVC), DLTS spectra using the technique of [4], the composition profiles of contact components by Auger electronic spectroscopy, the phase content of near-contact layers by SIMS, surface morphology of metal layers by the atomic forces microscopy using the Nanoscope D3000 device and PL spectra at $T=77 \mathrm{~K}$ were measured before and after thermal treatment.

\section{Experimental results and discussion}

In Fig. 1 forward and reverse IVC of Schottky barrier diodes (SD) Au-Mo- $\mathrm{TiB}_{\mathrm{x}}-\mathrm{GaAs}$ before and after thermal annealing at $T=400$ and $600{ }^{\circ} \mathrm{C}$ are shown. It can be seen that at low bias in an as-deposited sample and after annealing at $T=400$ ${ }^{\circ} \mathrm{C}$ the leakage current is observed in forward branches of 
E.F. Venger et al.: Effect of rapid thermal annealing on properties...

IVC. Its magnitude increases significantly after annealing at $T=600{ }^{\circ} \mathrm{C}$. In this case, the main part of the forward IVC deteriorates dramatically, as compared to as-deposited sample: the exponential part is much shorter, the barrier height $\varphi_{b}$ is lower, the ideality factor $n$ and saturation current $I_{s}$ increase (Table I). Similar changes are observed in the reverse branch of IVC. So, after annealing at $T=600{ }^{\circ} \mathrm{C}$ during $60 \mathrm{~s}$ significantly (practically by two orders of magnitude) increases the reverse current at the initial part of IVC.

Table 1. Parameters of forward branch of IVC of Mo-Au-TiB ${ }_{2}-$ GaAs contact before and after rapid thermal annealings.

\begin{tabular}{lcccc}
\hline \hline & $T\left({ }^{\circ} \mathrm{C}\right)$ & $n$ & $\varphi_{b}, \mathrm{eV}$ & $I_{s}, \mathrm{~A}$ \\
\hline 1 & As-deposited & 1.18 & 0.80 & $9.29 \cdot 10^{-12}$ \\
2 & 400 & 1.20 & 0.79 & $1.46 \cdot 10^{-11}$ \\
3 & 600 & 1.23 & 0.78 & $2.83 \cdot 10^{-11}$ \\
\hline
\end{tabular}

In order to ascertain the reasons of SD degradation, the CVC were measured before and after thermal treatments, and the impurity concentration was calculated from these characteristics. Parameters of deep centers were measured using deep level transient spectroscopy. It was found that the thermal treatment did not change the doping impurity concentration in the sample. However (see Table 2 and Fig.2), the energy spectrum and parameters of deep centers changed essentially in as-deposited and annealed samples, namely, instead of two centers with $E_{a} \sim 0.46 \mathrm{eV}$ and $0.85 \mathrm{eV}$ present in initial and annealed at $T=400{ }^{\circ} \mathrm{C}$ samples the new center with $E_{a} \sim 0.40 \mathrm{eV}$ appeared after the thermal annealing at $T=600{ }^{\circ} \mathrm{C}$. According to literature data, the level with $E_{a} \sim 0.85 \mathrm{eV}$ corresponds to the known deep center EL2 [5], and its parameters remained practically unchanged after annealing. Taking into account very close values of capture cross-sections, the levels with activation energy $E_{a}=0.46 \mathrm{eV}$ in as-deposited and with $E_{a}=0.44 \mathrm{eV}$ in the annealed sample seem to correspond to the same center of EL4 type [5]. And the center with activation energy $0.40 \mathrm{eV}$, generated in the result of thermal treatment at $T=600{ }^{\circ} \mathrm{C}$ causes the appearance of excess component of current at IVC and is close by its parameters to the known

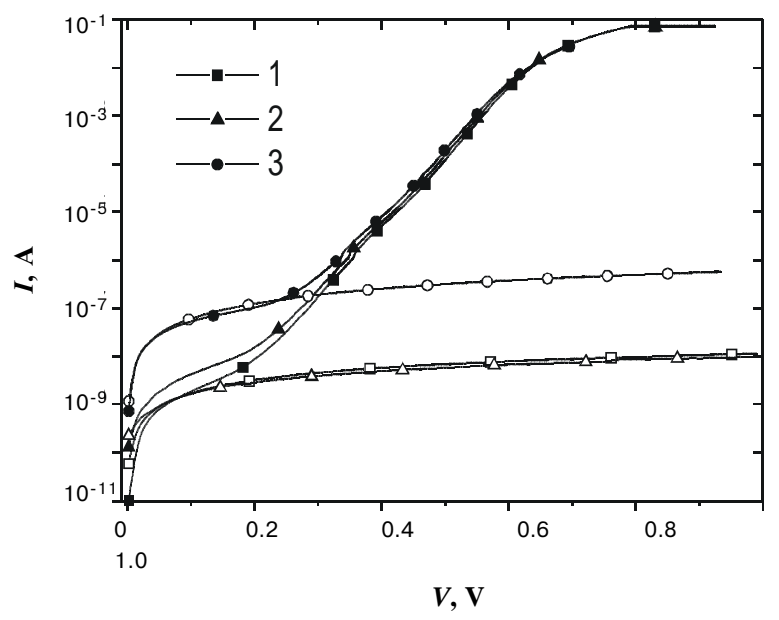

Fig.1. Forward (solid) and reverse (open) current-voltage characteristics of Au-Mo- $\mathrm{TiB}_{\mathrm{x}}-\mathrm{GaAs}$ contacts (1 - initial sample, 2 and 3 after annealing at $T=400,600{ }^{\circ} \mathrm{C}$, respectively, during $60 \mathrm{~s}$ in hydrogen atmosphere).

center EL5, representing, according to data of $[4,6]$ the complex $V_{\mathrm{Ga}}+V_{\mathrm{As}}$. The centers of similar nature are observed in the photoluminescense spectra after annealing at $T=600{ }^{\circ} \mathrm{C}$. In this case the intensity of the band $1.20 \mathrm{eV}$ in the annealed sample, related to $V_{\mathrm{Ga}}+V_{\mathrm{As}}$ complex, is by two orders of magnitude greater than the intensity of the band in as-deposited sample. The presence of the $V_{\mathrm{Ga}}+V_{\mathrm{As}}$ -type complex in the near-contact GaAs layer is also confirmed by the interphase interactions in the contact $\mathrm{TiB}_{\mathrm{x}}-\mathrm{GaAs}$ and relaxation of stress in the metallization layer, observed in the result of thermal treatment at $T=600{ }^{\circ} \mathrm{C}$. Really, the profiles of element distribution of the contact $\mathrm{Au}-\mathrm{Mo}-\mathrm{TiB}_{\mathrm{X}}-$ GaAs shown in Fig.3, obtained by Auger spectroscopy, indicate that in the initial (non-annealed) sample and in the sample thermally treated at $T=400{ }^{\circ} \mathrm{C}$ during $60 \mathrm{~s}$ profiles in the vicinity of $\mathrm{TiB}_{\mathrm{x}}-\mathrm{GaAs}$ interface are only slightly changed, whereas after thermal treatment at $T=600{ }^{\circ} \mathrm{C}$ during the same time in the interface the deviation from the stoichiometric composition of GaAs and «prolongation of the front» of $\mathrm{TiB}_{\mathrm{x}}$ into GaAs are observed. Annealing at $T=$ $800{ }^{\circ} \mathrm{C}$ lead to total intermixing of the contact components.

Table 2. Parameters of deep centers for Mo-Au-TiB $\mathbf{M}_{2}-\mathrm{GaAs}$.

\begin{tabular}{|c|c|c|c|c|c|}
\hline $\begin{array}{c}T \\
\left({ }^{\mathrm{o}} \mathrm{C}\right)\end{array}$ & $\begin{array}{c}N_{d}-N_{a} \\
\left(10^{16} \mathrm{~cm}^{-3}\right)\end{array}$ & $\begin{array}{c}E_{a} \\
(\mathrm{eV})\end{array}$ & $\begin{array}{c}\sigma_{a} \\
\left(10^{-14} \mathrm{~cm}^{-2}\right)\end{array}$ & $\begin{array}{c}N_{T} \\
\left(10^{14} \mathrm{~cm}^{-3}\right)\end{array}$ & Type of center \\
\hline $\begin{array}{c}\text { As- } \\
\text { deposited }\end{array}$ & 3.0 & $\begin{array}{l}0.46 \\
0.85\end{array}$ & $\begin{array}{c}4 \\
30\end{array}$ & $\begin{array}{c}3 \\
14\end{array}$ & $\begin{array}{l}\text { EL4 } \\
\text { EL2 }\end{array}$ \\
\hline 400 & 3.0 & $\begin{array}{l}0.46 \\
0.85\end{array}$ & $\begin{array}{c}4 \\
30\end{array}$ & $\begin{array}{c}3 \\
14\end{array}$ & $\begin{array}{l}\text { EL4 } \\
\text { EL2 }\end{array}$ \\
\hline 600 & 3.0 & $\begin{array}{l}0.40 \\
0.44 \\
0.85\end{array}$ & $\begin{array}{c}5 \\
4 \\
30\end{array}$ & $\begin{array}{c}8 \\
4 \\
13\end{array}$ & $\begin{array}{l}\text { EL5 } \\
\text { EL4 } \\
\text { EL2 }\end{array}$ \\
\hline
\end{tabular}




\section{E.F. Venger et al.: Effect of rapid thermal annealing on properties...}
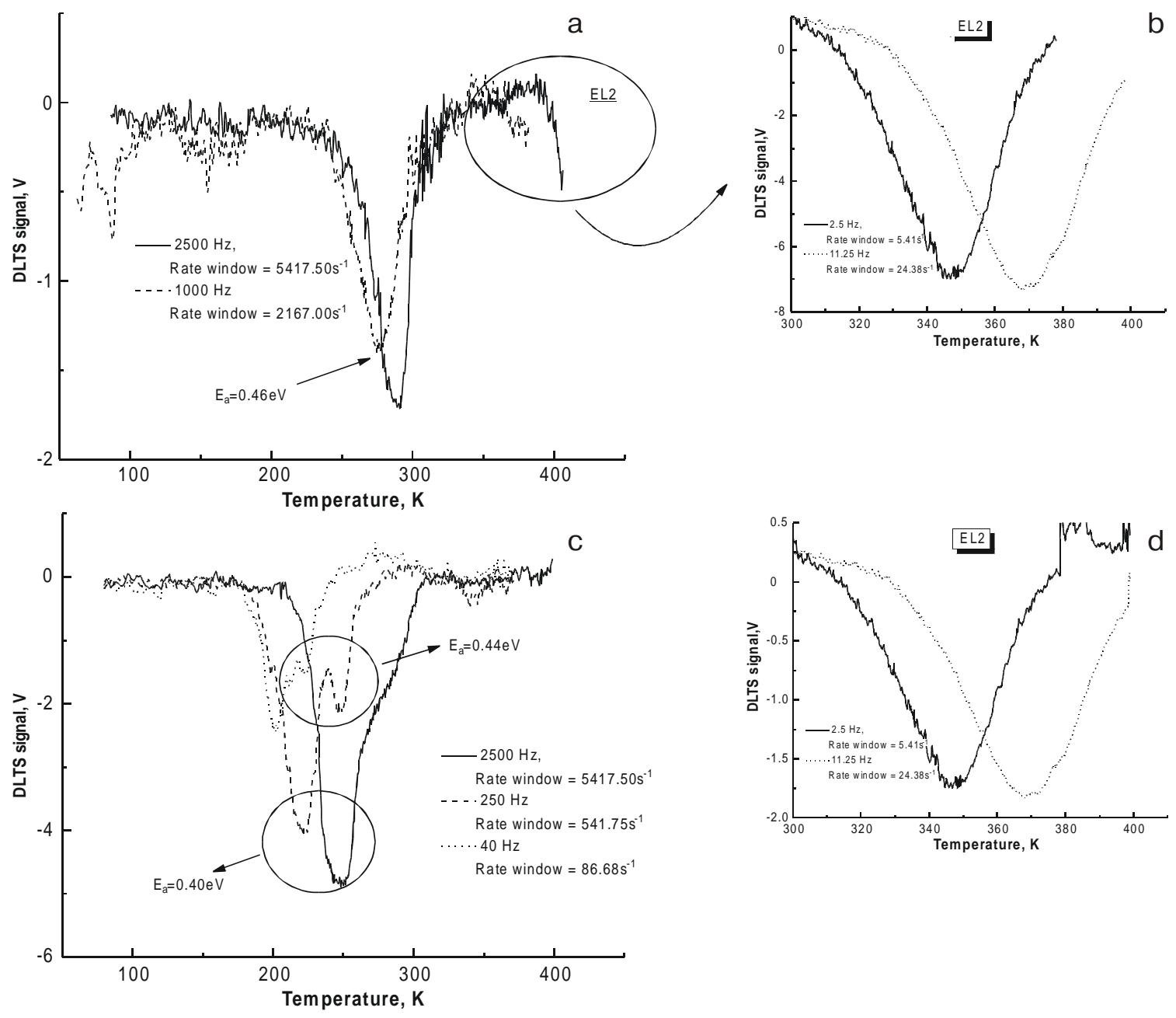

Fig.2. DLTS spectra of Au-Mo-TiB ${ }_{\mathrm{x}}-\mathrm{GaAs}$ contacts ((a)- initial sample, (c) - after annealing at $T=600{ }^{\circ} \mathrm{C}$ during $60 \mathrm{~s}$ in hydrogen atmosphere; (b), (d) - inserts of respective EL2 peaks).

Investigations of the phase composition in the near-contact layer, carried out using SIMS technique, have shown the presence of the phase $\mathrm{B}_{\mathrm{x}} \mathrm{Ga}_{1-\mathrm{x}} \mathrm{As}$ both in an as-deposited sample and after annealing at $T=600^{\circ} \mathrm{C}$, formation of which can be stimulated by the excess of Ga vacancies both at the stage of $\mathrm{TiB}_{2}$ film deposition and during its annealing. Note also that during annealing at $T=600{ }^{\circ} \mathrm{C}$ the relaxation of mechanical stresses in the contact system occurs accompanied by the cracking of the deposited metallic layers [7].

The morphology of the surface of initial and annealed at $T=400$ and $600{ }^{\circ} \mathrm{C}$ structures Au-Mo-TiB ${ }_{\mathrm{x}}-\mathrm{GaAs}$ was studied by the atomic force microscopy. It shows that in initial and annealed at $T=400^{\circ} \mathrm{C}$ samples no change of the structure of deposited layers is observed, but after annealing at $T$ $=600{ }^{\circ} \mathrm{C}$ microcracks are formed (Fig.4). This process results in generation of the structural defects in the near-contact region of GaAs, which are the generation-recombination centers and cause the increase of the extra currents in forward and reverse IVC.
It can be seen from the presented data that at least three physical factors determine the degradation mechanism of the barrier structures $\mathrm{Au}-\mathrm{Mo}-\mathrm{TiB}_{\mathrm{x}}-\mathrm{GaAs}$ after rapid annealing at $T=600{ }^{\circ} \mathrm{C}$ :

- generation of defects in the GaAs induced by rapid thermal annealing, including those with parameters $E_{a}=0.40 \mathrm{eV}, \sigma_{a}=5 \times 10^{-14} \mathrm{~cm}^{-2}, N_{t}=8 \times 10^{14} \mathrm{~cm}^{-3}$;

- deviation from the stoichiometric composition in the near-contact region of GaAs;

- relaxation of intrinsic mechanical stresses in the metallization layer, resulting in defect generation in the nearcontact region of $\mathrm{GaAs}$ and promoting the mass transfer in the contact region. 
E.F. Venger et al.: Effect of rapid thermal annealing on properties...
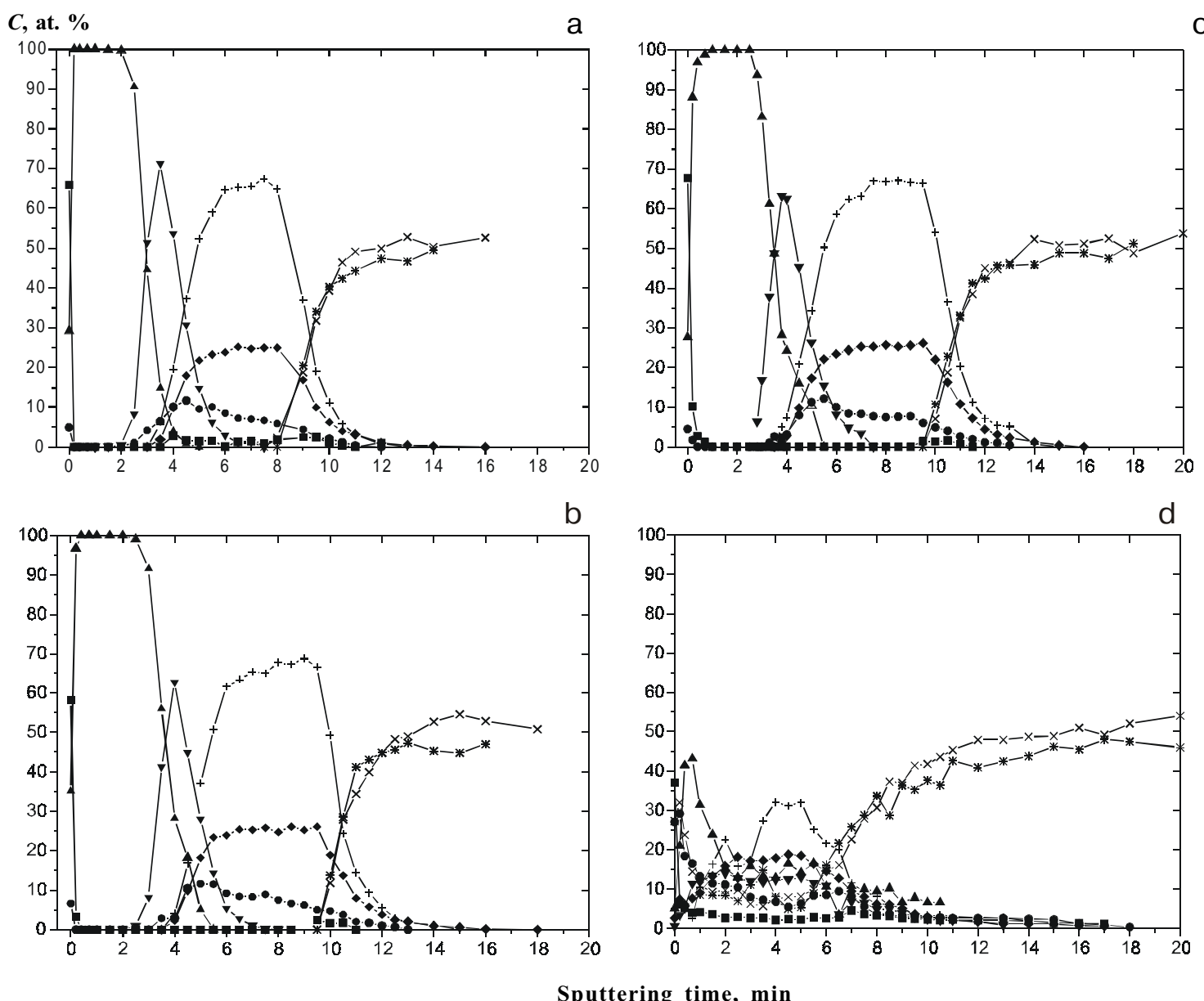

Sputtering time, min

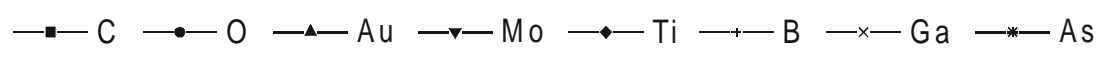

Fig.3. Concentration profiles of components of Au-Mo-TiB ${ }_{\mathrm{x}}-\mathrm{GaAs}$ contacts ((a) - initial sample, (b), (c) and (d) - after annealing at $T=400$, 600 and $800{ }^{\circ} \mathrm{C}$, respectively, during $60 \mathrm{~s}$ in hydrogen atmosphere).

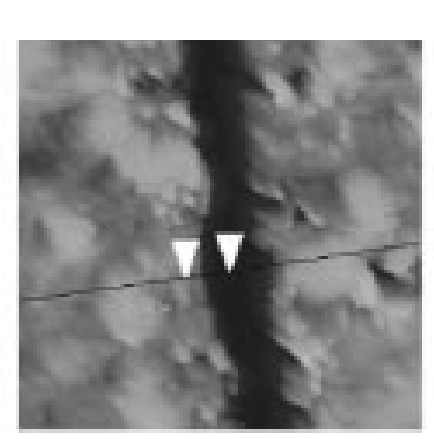

a

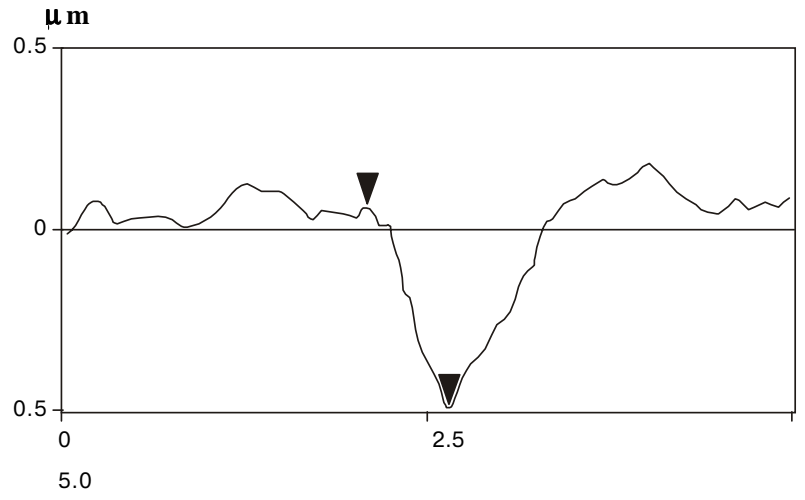

b $\mu \mathrm{m}$

Fig.4. Morphology of GaAs surface after removal of metallization (a) and microrelief at the surface of GaAs (b) along the line indicated by the arrows in (a). 


\section{E.F. Venger et al.: Effect of rapid thermal annealing on properties...}

\section{Conclusions}

The analysis of presented data shows that the contact system $\mathrm{Au}-\mathrm{Mo}-\mathrm{TiB}_{\mathrm{x}}-\mathrm{GaAs}$ is stable at rapid thermal treatment up to $T=400^{\circ} \mathrm{C}$ during $60 \mathrm{~s}$. The annealing at $600{ }^{\circ} \mathrm{C}$ for $60 \mathrm{~s}$ leads to appearance of extra currents of IVC, due to deep centers generated in the bulk of GaAs and in the near-contact layer.

The work is supported by STCU, project 464 .

\section{References}

1. Wiedemann R., Oettel H., Jerenz M. // Surface and Coatings Technology. 97(1-3), p.313-321 (1997).

2. Losbicher P., Mitterer C. // Surface and Coatings Technology. 97(13), p.567-573 (1997).
3. Hean C., Guillon N., Fillit R.Y., Machet J. // Surface and Coatings Technology. 97(1-3), p.60-65 (1997).

4. Wosinski T., Makosa A., Witczak Z. // Semicond. Sci. Techn. 9, p.2047-2052 (1994).

5. Martin G.M., Mittonneau A., Mircea A. // Electron. Lett. 13(7), p.191-192 (1997).

6. Marrakchi G., Kalboussi A., Bremond G., Guillot G., Alaya S., Maaref H., Fornari R. // J. Appl. Phys. 71, p.3325 (1992).

7. Venger E.F., Milenin V.V., Ermolovich I.B., Konakova R.V., Voitsikhovskiy D.I., Hotovy I., Ivanov V.N. // Semicond. Physics, Quant. Electron. \& Optoelectron., 2, p.124 (1999). 